\title{
Polarity formation by a higher order interaction Markov-like chain
}

\author{
Mathias Rech • Athanasios Batagiannis • \\ Jürg Hulliger
}

Received: 31 October 2008 / Accepted: 24 November 2008 / Published online: 11 December 2008 (C) Springer Science+Business Media, LLC 2008

\begin{abstract}
Vector property generation is discussed for chain growth by higher order interactions. Because of a deterministic property evolution a state space approach was used. Although not strictly Markovian, the system shows ergodic properties and convergence for a large number of attachment steps. For reasonable interaction energies attributed to increasing order, the main extra contribution to polarity formation results from interactions up to next nearest neighbours. Nonlinear equations up to third order were solved by an iterative procedure.
\end{abstract}

Keywords Markov chain - Macroscopic polarity formation $\cdot$ Higher order

\section{Introduction}

Building blocks $\mu$ representing a polar vector quantity $\vec{\mu}$ may self-assemble into a unidirectional linear chain by single attachment steps (Fig. 1). Parallel or antiparallel arrangement of $\vec{\mu}_{\mathrm{i}}$ ( $\mathrm{i}=1, \ldots$, q: number of building blocks) with respect to the direction $\vec{q}$ of growth can occur. The growth sequence builds up a strand containing the digital information $\mathrm{I}=\mathrm{q}$ and representing a polar state resulting from the sum $\sum \vec{\mu}_{\mathrm{i}}$ of vectors. A chemical representation of such a system can be found in different types of host crystals [1,2] providing parallel channels wherein dipolar molecules are included and can upon growth or loading undergo vectorial alignment along individual channels. Such chains were also observed for polar molecules in superfluid helium droplets [3].

M. Rech · A. Batagiannis · J. Hulliger $(\varangle)$

Department of Chemistry and Biochemistry, University of Berne, Freiestrasse 3,

Berne 3012, Switzerland

e-mail: publication.hulliger@iac.unibe.ch 
Fig. 1 Schematic representation of the guest-guest interactions

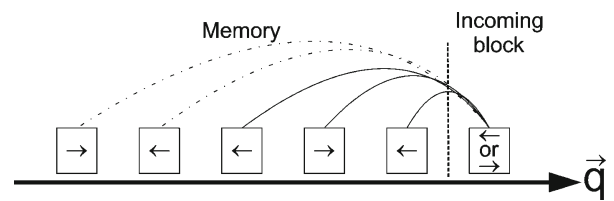

In a stochastic system and within the context of a probabilistic description the algorithm generating the sequence results from a set of probabilities $\mathrm{P}$ taking into account a certain degree of memory in the pre-existing chain. In the simplest case of a time (q) homogeneous Markov chain [4,5], we obtain [6-9]:

$$
\left(\begin{array}{l}
\left\langle\mu_{\uparrow}(\mathrm{q})\right\rangle \\
\left\langle\mu_{\downarrow}(\mathrm{q})\right\rangle
\end{array}\right)=\left(\begin{array}{ll}
\mathrm{P}_{11} & \mathrm{P}_{12} \\
\mathrm{P}_{21} & \mathrm{P}_{22}
\end{array}\right)^{\mathrm{q}}\left(\begin{array}{l}
\left\langle\mu_{\uparrow}(0)\right\rangle \\
\left\langle\mu_{\downarrow}(0)\right\rangle
\end{array}\right),
$$

where $\mathrm{q}$ is the number of individual steps $(1,2, \ldots, \infty)$ and $\mathrm{P}_{\mathrm{ij}}$ are the transition probabilities driving the system from step $\mathrm{q}$ to $\mathrm{q}+1$, etc. $\left(\mu_{\uparrow}:\right.$ parallel to $\overrightarrow{\mathrm{q}}, \mu_{\downarrow}$ : antiparallel to $\overrightarrow{\mathrm{q}}, \mu_{\uparrow}(0), \mu_{\downarrow}(0)$ : initial states at $\mathrm{q}=0,\langle\ldots>$ : statistical average).

In previous studies on polarity formation [6-8] in individual channels of host lattices, a Markov description involving interactions with only nearest members was assumed. In the present study, we investigate a system where attachment probabilities $\mathrm{P}$ account for a certain number $\xi$ of previously aligned building blocks. Consequently, we have to extend the transition matrix into a dimension of $2 \times 2 \xi$, operating on a column vector of $1 \times 2 \xi$. In view of describing the alignment of polar molecules this makes sense because of possible interactions of the incoming building block to that of level $\mathrm{q}-1, \mathrm{q}-2, \ldots, \mathrm{q}-\xi$. Given an exponential or $1 / \mathrm{r}^{3}$ decay of e.g. far reaching dipolar intermolecular interactions, a cut-off at $\xi=3$ is set here, since an extension to a higher order would not have a significant chemical impact. Also force field calculations show that the main energetic effect results from the first and the second coordination environment in molecular crystals [9].

\section{Higher order model for polarity formation}

For single attachment sites, the number of possible orientational states is 2 for $\xi=1,4$ for $\xi=2$ and 8 for $\xi=3$. All possible orientational states and corresponding symbols for attachment probabilities $\mathrm{P}_{\mathrm{ijk}}$ in the case of $\xi=2$ are listed in Fig. 2. For conditional probabilities we assume normalized Boltzmann factors:

$$
\mathrm{P}_{\mathrm{ijk}}=\frac{1}{1+\mathrm{e}^{ \pm \beta\left(\Delta \mathrm{E}_{\mathrm{j}}+\Delta \mathrm{E}_{\mathrm{k}}^{\prime}\right)}} \text { for all } \mathrm{i}, \mathrm{j}, \mathrm{k} \in\{\mathrm{A}, \mathrm{D}\} \text {, }
$$

where $\Delta \mathrm{E}_{\mathrm{A}}=\mathrm{E}_{\mathrm{AD}}-\mathrm{E}_{\mathrm{AA}}, \Delta \mathrm{E}_{\mathrm{A}}^{\prime}=\mathrm{E}_{\mathrm{AD}}^{\prime}-\mathrm{E}_{\mathrm{AA}}^{\prime}, \Delta \mathrm{E}_{\mathrm{D}}=\mathrm{E}_{\mathrm{AD}}-\mathrm{E}_{\mathrm{DD}}, \Delta \mathrm{E}_{\mathrm{D}}^{\prime}=\mathrm{E}_{\mathrm{AD}}^{\prime}-\mathrm{E}_{\mathrm{DD}}^{\prime}$, $\beta:=\frac{1}{\mathrm{RT}}$, the exponent sign being + for $\mathrm{i}=\mathrm{D}$ and - for $\mathrm{i}=\mathrm{A} . \mathrm{E}_{\mathrm{AA}}, \mathrm{E}_{\mathrm{DD}}, \mathrm{E}_{\mathrm{AD}}$ and $\mathrm{E}_{\mathrm{DA}}$ are the interactions of dipolar type molecules $\mathrm{A}-\pi-\mathrm{D}$ (A: acceptor, D: donor substituent) between the incoming guest and previously attached dipoles $(\xi=1)$; 


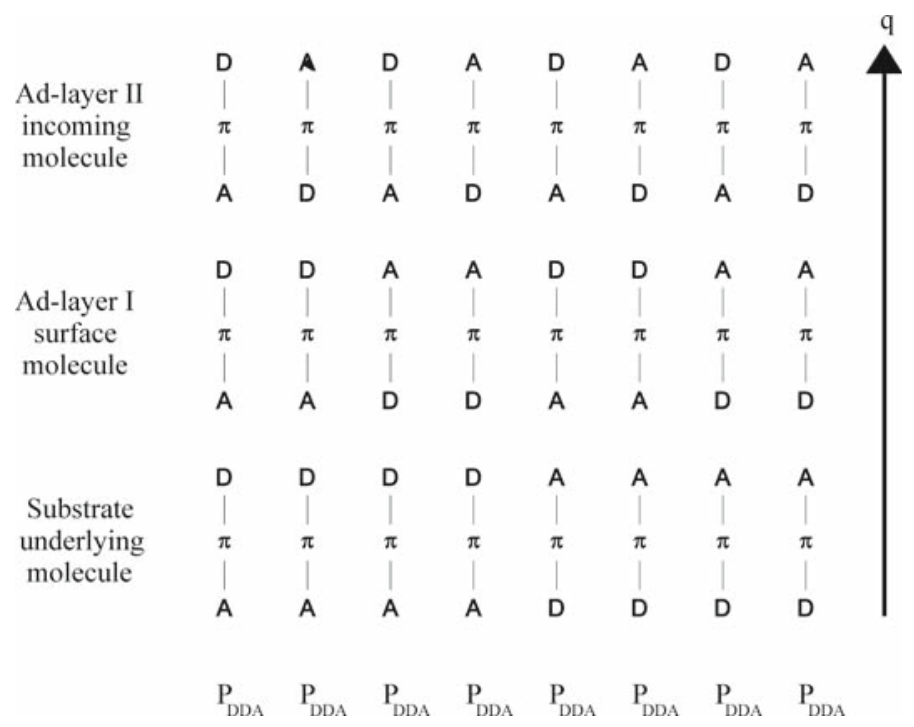

Fig. 2 Schematic representation of all possible interactions and corresponding probabilities in the case of $\xi=2$. Molecular building blocks are shown as A- $\pi-\mathrm{D}(\pi$ : conjugated spacer; A: acceptor group; D: donor group)

$\mathrm{E}_{\mathrm{AA}}^{\prime}, \mathrm{E}_{\mathrm{DD}}^{\prime}, \mathrm{E}_{\mathrm{AD}}^{\prime}$ and $\mathrm{E}_{\mathrm{DA}}^{\prime}$ are interactions of the incoming molecule with those at $\mathrm{q}-2$ $(\xi=2)$. $\mathrm{E}_{\mathrm{AD}}=\mathrm{E}_{\mathrm{DA}}$ and $\mathrm{E}_{\mathrm{AD}}^{\prime}=\mathrm{E}_{\mathrm{DA}}^{\prime}$. Note also that due to normalization we have:

$$
\sum_{\mathrm{k}=\mathrm{A}}^{\mathrm{D}} \mathrm{P}_{\mathrm{ijk}}=1 \text { for all } \mathrm{i}, \mathrm{j} \in\{\mathrm{A}, \mathrm{D}\} \text {. }
$$

Because of a stochastic description, we introduce fractional quantities $\mathrm{X}_{\mathrm{A}}(\mathrm{q})$ and $\mathrm{X}_{\mathrm{D}}(\mathrm{q})$ accounting for alignment of $\mu_{\uparrow}(\mathrm{q})$ and $\mu_{\downarrow}(\mathrm{q})$, with $\mathrm{X}_{\mathrm{A}}(\mathrm{q})+\mathrm{X}_{\mathrm{D}}(\mathrm{q})=1$.

As orientational states within strands of length $\xi$ are set by statistical averages $X_{i}(q-\xi)$, the probability of having a certain previous state of alignment at the attachment site (see Fig. 2) is thus given by products involving $X_{A}(q-\xi), X_{D}(q-\xi)$, respectively. Consequently, the matrix relation of Eq. 1 transforms into:

$$
\left(\begin{array}{l}
X_{A}(q) \\
X_{D}(q)
\end{array}\right)=\left(\begin{array}{llll}
P_{A A D} & P_{D A D} & P_{A D D} & P_{D D D} \\
P_{A A A} & P_{D A A} & P_{A D A} & P_{D D A}
\end{array}\right)\left(\begin{array}{ll}
X_{A}(q-1) & X_{A}(q-2) \\
X_{A}(q-1) & X_{D}(q-2) \\
X_{D}(q-1) & X_{A}(q-2) \\
X_{D}(q-1) & X_{D}(q-2)
\end{array}\right)
$$

using $X_{A}(q)=1-X_{D}(q)$ and solving the system of equations we get:

$$
\begin{aligned}
\mathrm{X}_{\mathrm{D}}(\mathrm{q})= & \left(\mathrm{P}_{\mathrm{DDA}}-\mathrm{P}_{\mathrm{DAA}}-\mathrm{P}_{\mathrm{ADA}}+\mathrm{P}_{\mathrm{AAA}}\right) \mathrm{X}_{\mathrm{D}}(\mathrm{q}-1) \mathrm{X}_{\mathrm{D}}(\mathrm{q}-2) \\
& +\left(\mathrm{P}_{\mathrm{ADA}}-\mathrm{P}_{\mathrm{AAA}}\right) \mathrm{X}_{\mathrm{D}}(\mathrm{q}-1)+\left(\mathrm{P}_{\mathrm{DAA}}-\mathrm{P}_{\mathrm{AAA}}\right) \mathrm{X}_{\mathrm{D}}(\mathrm{q}-2)+\mathrm{P}_{\mathrm{AAA}}
\end{aligned}
$$


which allows to calculate:

$$
\mathrm{X}_{n e t}(q):=\mathrm{X}_{\mathrm{A}}(\mathrm{q})-\mathrm{X}_{\mathrm{D}}(\mathrm{q})=1-2 \mathrm{X}_{\mathrm{D}}(\mathrm{q})
$$

$\mathrm{X}_{n e t}$ being the net fraction of polarity achieved by consecutive alignment of dipoles $\vec{\mu}_{i}$. A real physical property will be directly related to the average quantity $\mu \cdot \mathrm{X}_{n e t}(\mathrm{q})$.

In case of neglecting energies $\mathrm{E}_{\mathrm{ij}}^{\prime}$ the known one layer model [6-8] is obtained. Probabilities become equal pairwise, e.g. $\mathrm{P}_{\mathrm{DDA}}=\mathrm{P}_{\mathrm{ADA}}$ (former $\mathrm{P}_{\mathrm{DA}}$ ) and the $\xi=$ 2 molar fractions vanish since $X_{A}(q-2)+X_{A}(q-2)=1$. For $\xi=2$ Eq. 5 can be solved step wise, feeding the input of previous layers and starting by a random state for the substrate $(q=0)$. As Eq. 5 is not linear in $X_{i}(q-\xi)$, the asymptotic limit is one of the solutions of the quadratic fixed point equation:

$$
\begin{aligned}
& \left(\mathrm{P}_{\mathrm{DDA}}-\mathrm{P}_{\mathrm{DAA}}-\mathrm{P}_{\mathrm{ADA}}+\mathrm{P}_{\mathrm{AAA}}\right) \mathrm{X}_{\mathrm{D}}^{2} \\
& +\left(\mathrm{P}_{\mathrm{ADA}}+\mathrm{P}_{\mathrm{DAA}}-2 \mathrm{P}_{\mathrm{AAA}}-1\right) \mathrm{X}_{\mathrm{D}}+P_{\mathrm{AAA}}=0 .
\end{aligned}
$$

Thus the limit $\mathrm{X}_{n e t}$ of $\mathrm{X}_{n e t}$ (q) for $\mathrm{q} \rightarrow \infty$ is $\mathrm{X}_{n e t}=1-2 \mathrm{X}_{\mathrm{D}}$.

A similar set of equations can be derived including energies $\mathrm{E}_{\mathrm{AA}}^{\prime \prime}, \mathrm{E}_{\mathrm{DD}}^{\prime \prime}, \mathrm{E}_{\mathrm{AD}}^{\prime \prime}$ and $\mathrm{E}_{\mathrm{DA}}^{\prime \prime}$ describing interactions of the incoming molecule to guests at $\mathrm{q}-3$. The iteration formula for $\mathrm{X}_{\mathrm{D}}(\mathrm{q})$ becomes:

$$
\begin{aligned}
\mathrm{X}_{\mathrm{D}}(\mathrm{q})= & \left(\mathrm{P}_{\mathrm{DDDA}}-\mathrm{P}_{\mathrm{DDAA}}-\mathrm{P}_{\mathrm{DADA}}+\mathrm{P}_{\mathrm{DAAA}}-\mathrm{P}_{\mathrm{ADDA}}+\mathrm{P}_{\mathrm{ADAA}}+\mathrm{P}_{\mathrm{AADA}}\right. \\
& \left.-\mathrm{P}_{\text {AAAA }}\right) \mathrm{X}_{\mathrm{D}}(\mathrm{q}-1) \mathrm{X}_{\mathrm{D}}(\mathrm{q}-2) \mathrm{X}_{\mathrm{D}}(\mathrm{q}-3) \\
& +\left(\mathrm{P}_{\mathrm{ADDA}}-\mathrm{P}_{\mathrm{ADAA}}-\mathrm{P}_{\mathrm{AADA}}+\mathrm{P}_{\mathrm{AAAA}}\right) \mathrm{X}_{\mathrm{D}}(\mathrm{q}-1) \mathrm{X}_{\mathrm{D}}(\mathrm{q}-2) \\
& +\left(\mathrm{P}_{\mathrm{DADA}}-\mathrm{P}_{\mathrm{DAAA}}-\mathrm{P}_{\mathrm{AADA}}+\mathrm{P}_{\mathrm{AAAA}}\right) \mathrm{X}_{\mathrm{D}}(\mathrm{q}-1) \mathrm{X}_{\mathrm{D}}(\mathrm{q}-3) \\
& +\left(\mathrm{P}_{\mathrm{DDAA}}-\mathrm{P}_{\mathrm{DAAA}}-\mathrm{P}_{\mathrm{ADAA}}+\mathrm{P}_{A A A A}\right) \mathrm{X}_{D}(\mathrm{q}-2) \mathrm{X}_{\mathrm{D}}(\mathrm{q}-3) \\
& +\left(\mathrm{P}_{\mathrm{AADA}}-\mathrm{P}_{\mathrm{AAAA}}\right) \mathrm{X}_{\mathrm{D}}(\mathrm{q}-1)+\left(\mathrm{P}_{\mathrm{ADAA}}-\mathrm{P}_{\mathrm{AAAA}}\right) \mathrm{X}_{\mathrm{D}}(\mathrm{q}-2) \\
& +\left(\mathrm{P}_{\mathrm{DAAA}}-\mathrm{P}_{\text {AAAA }}\right) \mathrm{X}_{\mathrm{D}}(\mathrm{q}-3)+\mathrm{P}_{\mathrm{AAAA}}
\end{aligned}
$$

with conditional probabilities of the form:

$$
\mathrm{P}_{\mathrm{ijkl}}=\frac{1}{1+\mathrm{e}^{ \pm \beta\left(\Delta \mathrm{E}_{\mathrm{j}}+\Delta \mathrm{E}_{\mathrm{k}}^{\prime}+\Delta \mathrm{E}_{1}^{\prime \prime}\right)}} \text { for all } \mathrm{i}, \mathrm{j}, \mathrm{k}, \mathrm{l} \in\{\mathrm{A}, \mathrm{D}\}
$$

To the best of our knowledge, the present approach employing a higher-order chain to describe the evolution of a vectorial property has no precedent in literature. Higherorder Markov chains have been used extensively, mostly for the generation or prediction of sequences (e.g. language production [10], musical algorithmic composition [11], DNA mapping and sequence analysis [12-14] etc.). Most of the higher order models fall under two categories: state space and regenerative models [15]. Because of the linear, deterministic nature of further interactions the state space approach was used here. The system described here is non-Markovian and depends on a finite number of previous states. This "finite memory" justifies a deterministic stochastic model approach. 


\section{Numerical results}

In the case of interaction energies which reflect real chemical systems, Fig. 3 shows the behaviour for $\xi=1,2$ and 3. A dominant contribution is found for $\xi=2$, whereas for $\xi=3$ a minor correction is added. This justifies a formal treatment only up to $\xi=3$. Here we assume a typical long-range dipolar interaction for $\xi=2,3$ (as opposed to short-range dispersion and hydrogen bond type interactions) decreasing with distance as $1 / \mathrm{r}^{3}$ and an intermolecular (centre to centre) distance of about $10 \AA$. The results of Fig. 3 are typical for this system and show that $\mathrm{X}_{n e t}$ increases progressively with growth until it reaches a steady state.

The order of the vector alignment is quite uniform, especially for typically large $\mathrm{E}_{\mathrm{AD}}$-type interactions. However, for other cases numerous sequences can be generated. Because of next nearest and further interactions, the present system may give rise to phase transitions [16]. As dipolar vectors are assumed to be fixed in orientation once they have joined the chain, phase transitions by varying temperature after growth are not allowed here. However, a change of temperature during growth may introduce phenomena related to kinetic phase transitions [17].

In Fig. 4 the dependence of $\mathrm{X}_{n e t}$ on the crystallization temperature is shown. Consistent with previous results for the single layer system [18] a strong dependence on temperature is found offering to optimize net polarity by choosing an appropriate crystallization temperature. Figure 4 also reveals that systems involving higher order interactions show more resistance to the decrease of net polarity due to an increase of temperature.

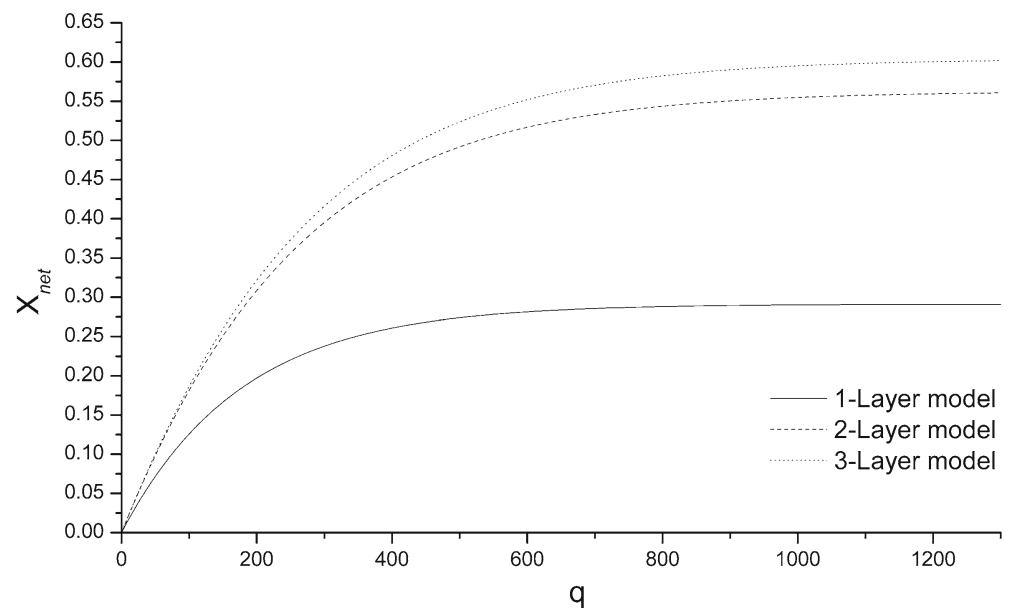

Fig. $3 \mathrm{X}_{\text {net }}$ plotted as a function of growth layers, q. Interaction energies: $\mathrm{E}_{\mathrm{AD}}=-15 \mathrm{~kJ} / \mathrm{mol}, \mathrm{E}_{\mathrm{AA}}=$ $0.5 \mathrm{~kJ} / \mathrm{mol}, \mathrm{E}_{\mathrm{DD}}=-1.0 \mathrm{~kJ} / \mathrm{mol}$. Interaction energies between the incoming molecule and the second and third layer are respectively $90 \%$ and $99 \%$ less than those between the incoming molecule and the first layer 


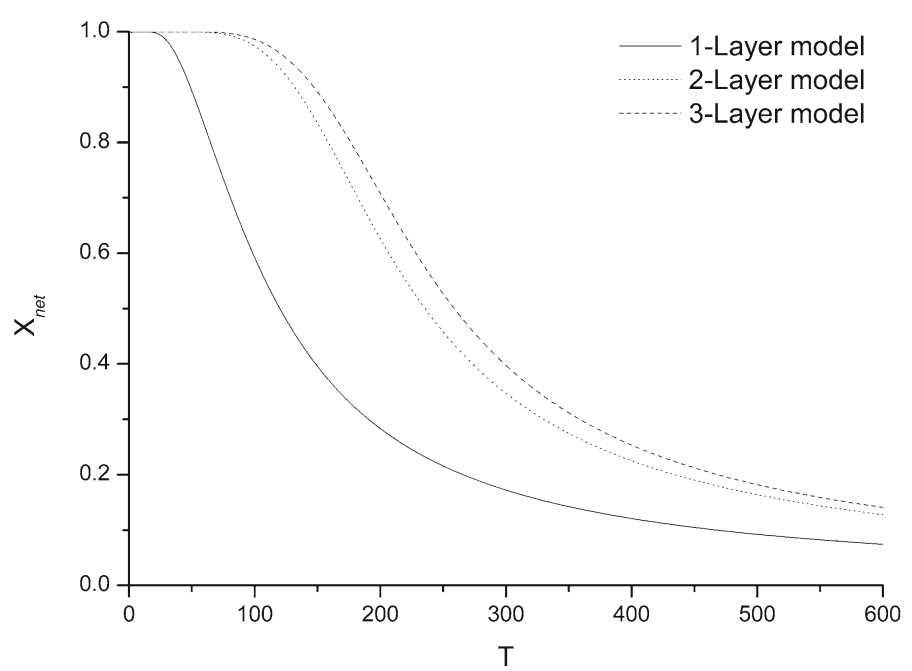

Fig. $4 \mathrm{X}_{\text {net }}$ plotted as a function of growth temperature. Interaction energies: $\mathrm{E}_{\mathrm{AD}}=-1.2 \mathrm{~kJ} / \mathrm{mol}, \mathrm{E}_{\mathrm{AA}}=$ $1.8 \mathrm{~kJ} / \mathrm{mol}, \mathrm{E}_{\mathrm{DD}}=0.6 \mathrm{~kJ} / \mathrm{mol}$. Interaction energies between the incoming molecule and the second and third layer are respectively $50 \%$ and $90 \%$ less than those between the incoming molecule and the first layer

\section{Summary and perspectives}

A state space [15] type model for a higher order interaction chain system is presented. Although not strictly Markovian, the system features main properties of a single Markov chain. Varying interaction parameters within a large possible domain a quasi ergodic behaviour and convergence for high $\mathrm{q}$ was found. As long as a reasonable energy range is considered for interactions $\mathrm{E}_{\mathrm{ij}}, \mathrm{E}_{\mathrm{ij}}^{\prime}$ and $\mathrm{E}_{\mathrm{ij}}^{\prime \prime}$, the main extra contribution results from the second order. It follows from Eqs. 2 and 9, that energies of different order add up to effective energies, which may enter a first order description as an approximation.

A logical extension of the present approach would be to include lateral interactions between adjacent chains by means of a mean-field description. This makes sense because realistic inter-channel distances are of the same order as inter-molecular distances along channels. Finally, this would end-up in a Monte Carlo simulation for growth, taking into account next-nearest interactions in both longitudinal and transversal direction. Present analyses are restricted to nearest neighbour models [19].

Acknowledgements This work received partial support from the regionale Arbeitsvermittlung and BNF for unemployed academics.

\section{References}

1. V. Ramamurthy, D.F. Eaton, Chem. Mater. 6, 1128-1136 (1994)

2. J. Hulliger, O. König, R. Hoss, Adv. Mater. 8, 719-721 (1995)

3. K. Nauta, R.E. Miller, Science 283, 1895-1897 (1999)

4. J.R. Norris, Markov Chains (Cambridge University Press, Cambridge, 1997) 
5. J.P. Sethna, Statistical Mechanics: Entropy, Order Parameters, and Complexity (Oxford University Press, Oxford, 2006)

6. K.D.M. Harris, P. Jupp, Proc. R. Soc. Lond. A 453, 333-352 (1997)

7. K.D.M. Harris, P. Jupp, Chem. Phys. Lett. 274, 525-534 (1998)

8. O. König, H.-B. Bürgi, T. Armbruster, J. Hulliger, T. Weber, J. Am. Chem. Soc. 119, 10632-10640 (1997)

9. C. Gervais, T. Wüst, N.-R. Behrnd, M. Wübbenhorst, J. Hulliger, Chem. Mater. 17, 85-94 (2005)

10. C.E. Shannon, AT\&T Tech. J. 27, 623-656 (1948)

11. L. Hiller, L. Isaacson, Experimental Music (McGraw-Hill, New York, 1959)

12. A.J. Cuticchia, R. Ivarie, J. Arnold, Nucleic Acids Res. 20, 3651-3657 (1992)

13. A. Shmilovici, I. Ben-Gal, Computation. Stat. 22, 49-69 (2007)

14. R. Durbin, S.R. Eddy, A. Krogh, G. Mitchison, Biological Sequence Analysis: Probabilistic Models of Proteins and Nucleic Acids (Cambridge University Press, Cambridge, 1999)

15. S.P. Meyn, R.L. Tweedie, Markov Chains and Stochastic Stability (Springer-Verlag, London, 1993)

16. I. Leike, F. Marlow, Zeolites 16, 65-69 (1996)

17. Z. Chvoj, J. Šesták, A. Tř́íska, Kinetic Phase Transitions (Elsevier, New York, 1991)

18. A. Batagiannis, T. Wüst, J. Hulliger, J. Math. Chem. (in press). doi:10.1007/s10910-008-9433-0

19. H. Bebie, J. Hulliger, S. Eugster, M. Alaga-Bogdanović, Phys. Rev. E 66, 021605-1-021605-10 (2002) 